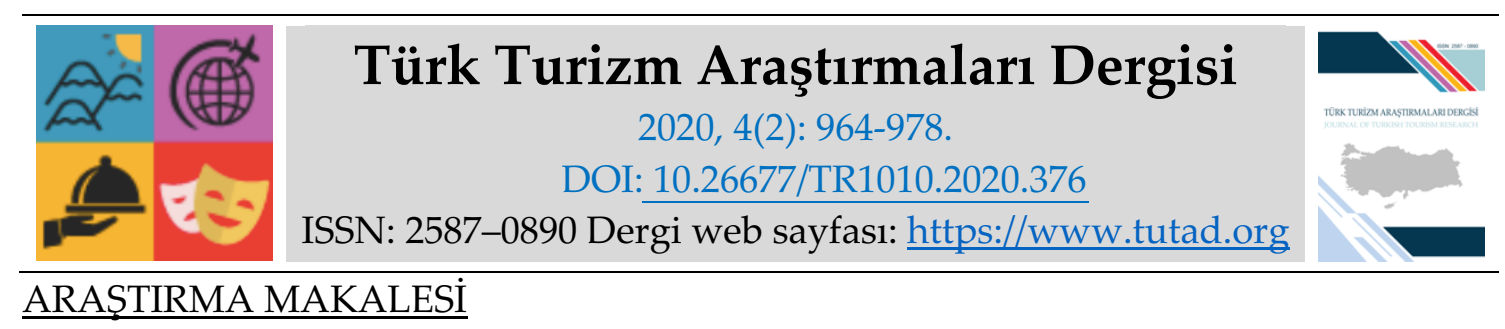

\title{
Festival Katılımcılarının Deneyim Temelli Sınıflandırılması
}

Arş. Gör. Dr. Kübra AŞAN, Sinop Üniversitesi, Turizm İşletmeciliği ve Otelcilik Yüksekokulu, Sinop, e-posta kubra.asan@hotmail.com ORCID: https://orcid.org/0000-0002-8739-3585

Prof. Dr. Medet YOLAL, Anadolu Üniversitesi, Turizm Fakültesi, Eskişehir, e-posta myolal@anadolu.edu.tr

ORCID: https://orcid.org/0000-0002-9834-2425

$\ddot{O} z$

Festivaller işletme, katılımcı ve yerel halka kazandırdığı sosyal, ekonomik ve kültürel faydalar nedeniyle yükselen bir trende sahiptir. Artan festival sayısı ve çeşitliliği rekabet ortamı yarattı̆̆ından, tüketici yönelimli pazarlama stratejilerine göre festival katılımcıları üzerinde pazar bölümlendirme çalışmaları yapmak organizatörler için fayda sağlayacaktır. Buradan hareketle çalışmada deneyim ekonomileri yaklaşımı kapsamında incelenen festival deneyimleri temel alınarak festival katılımcıları üzerinde bir bölümlendirme araştırması yapılması amaçlanmıştır. Bu amaçla Türkiye' de Sinop kentinde gerçekleşen Kuzeyfest Rock Müzik Festivali örneğinde bir alan araştırması yürütülmüştür. Anket tekniğiyle toplanan veriler üzerinde, faktör analizi, kümeleme analizi, ki-kare ve t-test analizi uygulanmıştır. Analiz sonucunda katılımcıların, deneyimleri ve çeşitli sosyo-demografik özellikleri kapsamında "aktif deneyimciler" ve "pasif deneyimciler" olmak üzere iki gruba anlamlı bir şekilde ayrılabildiği görülmüştür. Buna göre genç, bekar ve öğrenci oldukları görülen pasif deneyimciler, daha çok eğlence deneyimi yaşarken; eğitim düzeyi yüksek, çalışma hayatında yer alan ve yaş ortalaması nispeten yüksek olan aktif deneyimcilerin daha çok eğitim ve kaçış deneyimi yaşadığı sonucuna ulaşılmıştır.

Anahtar Kelimeler: Etkinlik Yönetimi, Pazar Bölümlendirme, Festival, Deneyim, Deneyim Ekonomileri.

Makale Gönderme Tarihi: 18.01 .2020

Makale Kabul Tarihi: 09.04.2020

\section{Önerilen Atıf:}

Aşan, K. ve Yolal, M. (2020). Festival Katılımcılarının Deneyim Temelli Sınıflandırılması, Türk Turizm Araştırmaları Dergisi, 4(2): 964-978.

(C) 2020 Türk Turizm Araştırmaları Dergisi. 


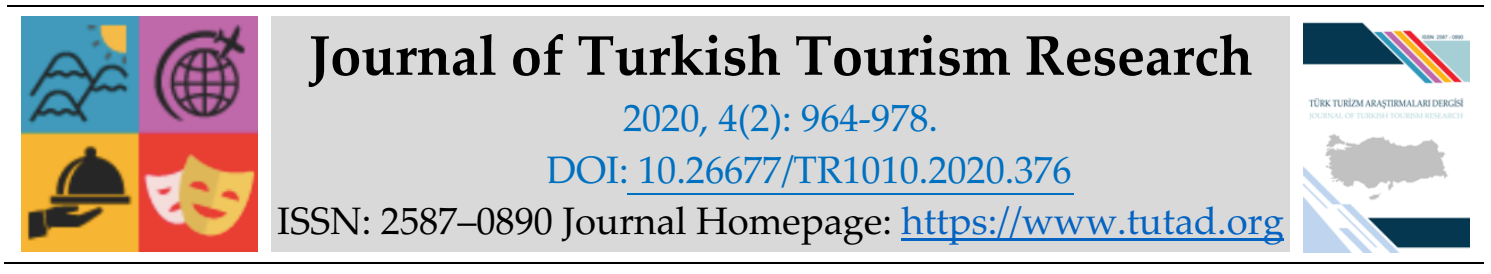

\title{
$\underline{\text { RESEARCH PAPER }}$
}

\section{Experience Based Segmentation of Festival Participants}

Dr. Kübra AŞAN, Sinop University, School of Tourism and Hotel Management, Sinop, e-mail kubra.asan@hotmail.com

ORCID: https://orcid.org/0000-0002-8739-3585

Prof. Dr. Medet YOLAL, Anadolu University, Faculty of Tourism, Eskişehir, e-mail myolal@anadolu.edu.tr

ORCID: https://orcid.org/0000-0002-9834-2425

\begin{abstract}
Festivals have become popular due to their social, economic and cultural benefits for both the visitors and the local residents. As the increasing number and diversity of festivals create a competitive environment, market segmentation based on consumer-oriented marketing strategies is advantageous for festival organizers. From this point of view, this study aimed to offer a segmentation analysis of festival participants on their festival experiences within the confines of experience economy. For the purpose of the paper, a field study was carried out in the case of the Kuzeyfest Rock Music Festival in Sinop, Turkey. Descriptive analysis, factor analysis, cluster analysis, chi-square and t-test analysis were applied to the data collected by the survey technique. Findings revealed that participants could be segmented into two groups as "active experiencers" and "passive experiencers" on the basis of their experiences and sociodemographic characteristics. Findings also showed that passive experiencers were young, single and students, and mostly entertained themselves while passive experiencers were employed, highly educated and middle aged and mostly experience education and escape.
\end{abstract}

Keywords: Event Management, Market Segmentation, Festival, Experience, Experience Economy.

Received: 18.01 .2020

Accepted: 09.04.2020

\section{Suggested Citation:}

Aşan, K. and Yolal, M. (2020). Experience Based Segmentation of Festival Participants, Journal of Turkish Tourism Research, 4(2): 964-978.

(C) 2020 Türk Turizm Araştırmaları Dergisi. 


\section{Gíriş}

Festivaller, kentsel gelişim, turizm, destinasyon pazarlaması, etkinlik yönetimi bağlamında incelenen etkinliklerdir (Getz, 2008). Festivaller "sınırlı bir süreyi kapsayan, belli bir temanın kutlanması için halkın davet edildiği etkinlikler" şeklinde tanımlanmaktadır (Grappi ve Montanari, 2011: 1129). Dünyadaki pek çok destinasyon büyüyen festival pazarından pay kapmak ve ziyaretçileri çekmek için festivaller organize etmektedir (Dieck, Jung ve Rauschnabel, 2018). Bu doğrultuda festivaller destinasyon için çekici bir unsur ya da başlı başına turistik ya da rekreatif bir ürün olarak sunulmaktadır.

Etkinlik türlerinden biri olan festivaller hem ziyaretçi hem de ev sahibi halk için çeşitli faydalar sağladığından festivallerin sayısı ve çeşitliliği gün geçtikçe artmaktadır (Gursoy, Kim ve Uysal 2004). Sahip olduğu doğal, tarihi ve kültürel kaynaklarıyla etkinlik turizmi anlamında önemli bir potansiyele sahip olan Türkiye'de, yılda 1400 civarında farklı ölçeklerde etkinlikler düzenlenmektedir (Yolal, 2017). Bu etkinliklerden biri olan festivaller çerçevesinde artan sayı ve çeşitlilik rekabet ortamı yaratmaktadır. Rekabet ortamında avantaj sağlamak adına tüketici yönelimli pazarlama stratejilerinden biri olan hedefli pazarlama önerilmektedir (Yükselen, 2010). Buna göre farklılıklar dikkate alınarak homojen gruplar oluşturmak için pazar bölümlendirmesi yapılması katılımcıların ihtiyaçlarını anlayıp cevap vermeyi kolaylaştırmaktadır. Bu bağlamda pazar bölümlendirmesi için başvurulabilecek çok sayıda değişken bulunmaktadır. Deneyimler, bu değişkenlerden biri olarak öne çıkmaktadır (Lee, Jan, Tseng ve Lin, 2018; Kastenholz, Carneiro ve Eusébio, 2018; Arnould ve Price, 1993).

Festivaller özünde deneyimsel ürünlerdir (Park, Oh ve Park, 2010; Rivera, Semrad ve Croes, 2015; Manthiou, Lee, Tang ve Chiang, 2014). Deneyim, katılımcları ve katılımcılarla çevreleri arasındaki etkileşimin bir sonucu olarak gelişen zihinsel bir durumu ifade etmektedir (Lee ve Shafer, 2002). Ayrıca deneyimler, aktivite, algı, anlam, güdü ve değerlendirme gibi kavramlarla da açıklanabilmektedir (Elands ve Lengkeek, 2012:31). Buna göre festival katılımcılarının, festival ortamında yaşadığı etkileşimlerden edindiği anlam, alg1 ve değerlendirmeler festival deneyimlerini oluşturmaktadır. Pazarlama literatürüne bakıldığında, deneyim tüketici davranışının en önemli unsurlarından biri olarak görülür. Geçmiş deneyimlerle oluşan bilgi ile yeniden tüketim davranışının güdülendiği; kişisel deneyimlerin birey için daha güvenilir olduğu ve yeni tüketim kararı üzerinde etkili olduğu görülmektedir (Kim, Ritchie ve McCormick, 2012). Dahası deneyim, tüketime konu olan başlı başına bir ürün olarak kabul görmektedir (Toffler, 1981; Holbrook ve Hirschman, 1982; Pine ve Gilmore, 1998). Bu bağlamda öne çıan teorik açıklamalardan biri Pine ve Gilmore'ın (1998) deneyimlerin ekonomik bir sunu türü olarak alıcılara göre tasarlanıp sahnelenebileceğini içeren deneyim ekonomileri modelidir. Buna göre katılımclların zihninde benzersiz ve unutulmaz bir festival deneyimi yaratmak mümkündür (Morgan, 2008; Rivera vd., 2015). Katılımcıların festival alanında bulunan etkinliklere katılım düzeyi ve festival ortamı ile olan ilişkisinin düzeyine göre farklı deneyimler -eğitim, estetik, eğlence, kaçış- yaşayabileceğini öne süren bu yaklaşım, farklı alanlara uyarlanabilir olduğundan "mega" bir yaklaşım şeklinde betimlenmektedir (Mehmetoglu ve Engen, 2011).

Etkinlik ve festival üzerine yapılan çalışmalarda deneyim sıklıkla incelenen bir konu olmuştur. Özellikle deneyim ekonomileri modeli ile festival deneyimlerini açılayan ampirik çalışmalar yapıldığı görülmektedir (Dieck vd., 2018; Rivera vd., 2015; Manthiou vd., 2014; Mehmetoğlu ve Engen 2011; Park vd., 2010). Bu çalışmalar etkinlik deneyimlerinin farklılaşabildiğini göstermektedir. Farklılaşan bu deneyimlerin, festival pazarını oluşturan katılımcıların anlamlı bir şekilde homojen gruplara ayrılması için başvurulabilecek bir değişken olabileceği tahmin edilmektedir. Ancak literatürde deneyimleri temel alan bir pazar bölümlendirme çalışması yok 
denecek kadar azdır. Buradan hareketle bu çalı̧̧mada bir müzik festivali örneğinde, katılımcıların deneyimlerine göre sınıflandırılması amaçlanmıştır.

Çalışmanın amacı doğrultusunda Sinop'ta gerçekleşen Kuzeyfest Rock Müzik Festivali örneğinde bir alan araştırması yürütülmüştür. Çalışmanın sonucunda katılımcıların, başvurulan deneyim ekonomi modelinin teorik çerçevesine göre gruplanabileceği tahmin edilmektedir. Çalışmada festival organizatörleri için, hedef kitlelerini daha iyi anlayabilmeleri ve buna uygun olarak sundukları hizmeti iyileştirmeleri için öneriler geliştirilebilecek çıtılar elde edilmesi hedeflenmektedir. Ayrıca çalışmanın etkinlik yönetiminde katılımcı davranışı literatürüne katkı sağlaması düşünülmektedir.

\section{PAZAR BÖLÜMLENDİRME}

Pazar bölümlendirme rekabet avantajı sağlamak adına tüketici merkezli bir yaklaşım olan hedefli pazarlamanın önemli bir aşamasıdır (Eser, Korkmaz ve Öztürk, 2011; Yükselen, 2010). Hedefli pazarlama tüketicileri belirli özelliklerine göre homojen bölümlere ayırma ve bu bölümlerden bir ya da birkaçını seçerek her bir bölüm için uygun ürünler sunmayı içermektedir. Bu süreç içinde yer alan pazar bölümlendirme, "ayrı pazarlama stratejileri ya da karma unsurlarının gerektirdiği, farklı ihtiyaç, özellik ve davranışa göre bir pazarı, daha küçük bölümlere ayırmak" şeklinde tanımlanmaktadır (Kotler ve Armstrong, 2010: 262). Bu haliyle pazar bölümlendirme uygulayıcıların belli bir noktaya yoğunlaşmasını ve bütçelerini etkin bir şekilde kullanmalarını sağlamaktadır (Sung, Morrison ve O'Leary, 2001).

Turizm ve boş zaman endüstrisi kapsamında tüketici pazarını, erişilebilir küçük ve homojen gruplara ayırmak mümkündür. Bu noktada literatürde coğrafik, psikografik, demografik ve davranışsal değişkenlere göre çok sayıda bölümlendirme yapılabileceği görülmektedir (Kotler ve Armstrong 2010; Reid ve Bojanic, 2006; Morrison, 1996; Swarbrooke ve Horner, 2007). Değişkenlerin sıklıkla iç içe geçmesi ve/veya birbirlerini desteklemesi nedenlerinden ötürü turizm pazarlaması açısından en önemli pazar bölümlendirme değişkenini belirlemek oldukça güçtür (Sung vd., 2001: 4). Öte yandan turizmde pazar bölümlendirme çalışmalarını ele alan çalışmalarında Dolnicar ve Kemp (2009) psikografik ve davranışsal değişkenlerin, en sık kullanılan değişkenler olduğunu ifade etmektedirler. Ayrıca Swarbrooke ve Horner (2007) da davranışsal değişkenlerin uygulamada sıklıkla tercih edildiğini belirtmektedirler. Davranışsal değişkenler içinde, deneyim temelli pazarlama yaklaşımlarının etkisiyle deneyimlerin bir ölçüt olarak öne çıktığı görülmektedir.

Deneyimler, turist davranışının daha iyi anlaşılmasını sağlamak amacıyla geliştirilen turist tipolojilerinde de temel alınan bir değişkendir (Prentice, Witt ve Hamer, 1998). Ancak Swarbrooke ve Horner (2007: 7) turist tipolojileri ve pazar bölümlendirmenin farklı yaklaşımlar olduğuna dikkat çekerek turizmin, turist tipolojilerinde sosyal bir olgu; pazar bölümlendirmede ise arz sağlayıcılarını ilgilendiren ekonomik bir olay olarak görüldüğünü ifade etmektedirler. Benzer şekilde Witt ve Moutinho (1995: 295) pazar bölümlendirme ve turist tipolojilerinin ayrımına odaklanmışlar, tipolojilerin bir genelleme süreci olduğunu, bölümlendirmenin ise bir detaylandırma süreci olduğunu ifade etmişlerdir.

Literatür incelendiğinde az sayıda olmakla birlikte deneyim temelli bölümlendirme çalışmalarına erişmek mümkündür. İlk olarak Tayvan'da Liuqiu adasında rekreasyon deneyimi temelli bir pazar bölümlendirme çalışması yapan Lee ve arkadaşları (2018), adaya gelen turistlerin anlamlı bir şekilde dört gruba ayrıldığı sonucuna ulaşmışlardır. Çalışmada bu grupların çoklu deneyim, estetik deneyim, hedonik deneyim ve bilgilenme deneyimi arayan rekreasyonistler şeklinde adlandırıldığı görülmektedir. Kastenholz vd., (2018) ise kırsal turizm örneğinde yerel halkla 
yaşadıkları etkileşim deneyimine göre turistlere yönelik bir bölümlendirme çalışması yapmışlardır. Buna göre kırsal turizm pazarında içedönük, turist odaklı ve yerel halk odaklı deneyimler yaşayan turist bölümlerinin olduğu görülmüştür. Bir başka çalışmada ise Arnould ve Price (1993) Yunan yaz kamplarına katılanların yaşadıkları sıra dışı deneyimlere göre kampçıların sosyal-doğal, kayıtsız, saf-doğal ve maceracılar şeklinde sınıflandığını saptamışlardır. Öte yandan literatürde festival/etkinlik katılımcıları üzerinde deneyim temelli bir sınıflandırma çalışmasına ulaşılamamıştır.

\section{Deneyim Ekonomileri Kapsamında Festival Deneyimi}

Pine ve Gilmore (1998) tarafından geliştirilen deneyim ekonomileri modeli, rekabet avantaj1 sağlamak adına ekonomik bir ürün olarak kabul edilen deneyimler üzerine kuruludur. Temelde tüketiciler için unutulmaz deneyimlerin yaratılabileceği fikrine dayanan bu yaklaşım, çok farklı tüketim alanlarında uygulanması mümkün sistematik bir model olarak dikkat çekmekte ve bir mega akım olarak görülmektedir (Mehmetoglu ve Engen, 2011). Bu model turizm ve boş zaman çalışmalarında da sıklıkla kullanılan teorik bir çerçeve sunmaktadır (Jung, Dieck, Lee ve Chung, 2016).

Pine ve Gilmore (2011) deneyimleri iki boyut içinde açılamaktadır. Bu boyutlar katılım ve ortam ilişkisi boyutlarıdır (Şekil 1). Katılım boyutunda, bireylerin bir etkinliğe aktif ya da pasif bir şekilde katıldıkları görülmektedir. Bireyler deneyim ortamı içinde, deneyimle zayıf bir ilişki kurarak özümseme ya da deneyimin duygu ve heyecanını oldukça fazla hissederek güçlü bir sarmalanma ilişkisi kurabilmektedirler. Bu boyutları birleştirdiklerinde bir matris elde eden Pine ve Gilmore (2011) matris içindeki dört alanın her birinin ayrı özellikte bir deneyimi ifade ettiğini, zengin bir deneyim için tüm deneyim boyutlarına hitap edilmesi gerektiğini ileri sürmektedirler. Bu deneyimler, eğitim, eğlence, estetik ve kaçış deneyimleridir.

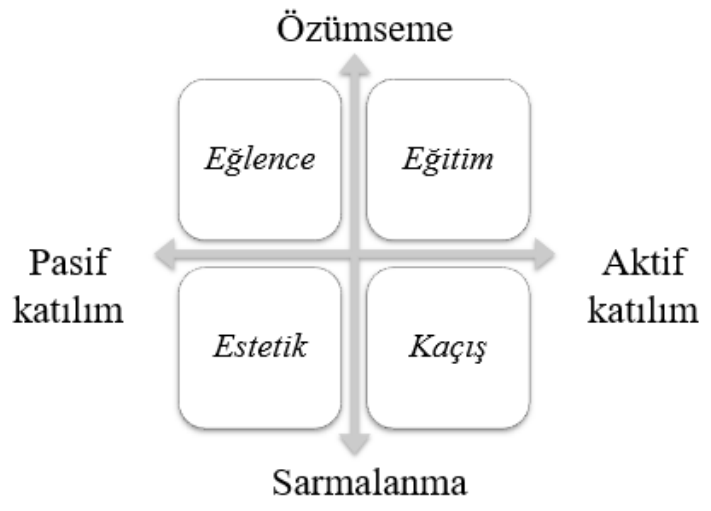

Şekil 1. Deneyim Ekonomileri Modeli

Kaynak: Pine ve Gilmore, 2011: 72.

Model kapsamında ilk olarak deneyimin eğlence boyutunun ortam ilişkisi açısından özümseme, katılım açısından da pasif katılımla oluştuğu görülmektedir (Oh, Fiore ve Jeoung, 2007). Eğlence deneyiminde katılımcıların, etkinlik deneyimlerinin çekiciliklerine yoğunlaştıkları düşünülmektedir (Hwang ve Lee, 2019). Festival deneyimleri temelinde ele alındığında 
katılımcıların etkinlikte yer alan gösterileri, performansları ya da diğer katılımcıları izleyerek hoşça vakit geçirmeleriyle eğlence deneyimi açılanmaktadır (Rivera vd., 2015).

Estetik deneyimlerde ise pasif katılımla birlikte, bireylerin ortamla güçlü bir ilişki kurarak sarmalandıkları görülmektedir (Dieck vd., 2018). Festival deneyimi olarak estetik, katılımcıların festivalin gerçekleştirildiği fiziksel çevreyi algılamaları ve değerlendirmelerini içermektedir. Manthiou vd. (2014) estetik deneyimlerin "serviscape" ya da "festivalscape" terimleriyle de açıklanabileceğine işaret etmektedirler. Buna göre estetik deneyimler festival alanının fiziksel unsurlarının yanı sıra hizmet imkânlarını da kapsayabilmektedir.

Üçüncü olarak modelde aktif katılım ve sarmalanmanın birlikte görülmesiyle kaçış deneyimleri ortaya çıkmaktadır. Buna göre katılımcılar, aktif bir şekilde etkinlik ortamının içine çekilmekte ve ortam unsurları ile sarmalanmaktadırlar. Öte yandan kaçış deneyimleri turizm literatüründe sıklıkla karşılaşılan bir deneyim türüdür (Park vd., 2010; Getz, 2008; Iso-Ahola, 1983). Turizmde kaçış, insanların olağan hayatlarının dışına çıkma güdüsü ile katıldıkları turizm deneyimlerini ifade etmektedir. Bu duruma benzer şekilde etkinlik ya da festival söz konusu olduğunda da katılımcıların gündelik hayatlarından farklı yaşantılar içinde olma arzusu ile kaçış deneyimi yaşaması mümkündür (Rivera vd., 2015).

Son olarak modelde yer alan eğitim deneyimi, ziyaretçilerin yeni bilgi ve beceriler kazanarak aktif bir şekilde etkinliklere katılım gösterdikleri deneyimleri ifade etmektedir (Oh vd., 2007). Buna göre yeni şeyler öğrenme arzusuyla katılımcılar, etkinlik veya performanslara yönelmektedir (Hwang ve Lyu, 2015). Katılımcıların çevreyle olan ilişkisi ise kaçış deneyimine göre daha düşük düzeyde, özümseme şeklindedir (Pine ve Gilmore, 2011).

Deneyim ekonomileri yaklaşımı, turist deneyimlerinin açıklanmasında çok sayıda turizm çalışmasının başvurduğu bir yaklaşımdır (Hwang ve Lee, 2019; Duan, Arcodia, Ma ve Hsiao 2018; Hwang ve Lyu 2015; Aşan ve Emeksiz, 2018). Son yıllarda yapılan çalışmalara örnek olarak, Hwang ve Lyu (2015) golf turnuvası katılımcılarına yönelik gerçekleştirdiği ampirik çalışmasında eğitim, eğlence ve kaçış deneyimi yaşayan katılımcıların yaşadıkları bu deneyimlerin yaşam memnuniyet algısı üzerinde etkili olduğu sonucuna ulaşmıştır. Benzer şekilde deneyim ekonomileri modelini temel alarak şarap turizmi üzerine çalışan Duan vd., (2018) ise sanal topluluklar üzerinde yaptıkları incelemelerde eğitim, eğlence ve estetik deneyimlerin öne çıktığını ortaya koymuştur. Aşan ve Emeksiz'in (2018) doğa etkinlikleri katılımcıları özelinde yaptıkları çalışmada ise eğitim, estetik ve kaçış deneyimleri görülmüştür. $\mathrm{Bu}$ çalışmalara göre çeşitli turizm ve rekreatif etkinliklerde deneyim ekonomileri yaklaşımının katılımcı deneyimlerinin açıklanması anlamında iyi bir teorik çerçeve olduğu görülmektedir.

Deneyim ekonomileri kapsamında özel olarak festival/etkinlik deneyimlerinin açıklanabileceğini kanıtlayan ampirik çalışmalar da mevcuttur (Dieck vd., 2018; Rivera vd., 2015; Manthiou vd., 2014; Mehmetoğlu ve Engen 2011; Park vd., 2010). Bu çalışmaların alan araştırmalarının genelde turizm, kültür ve sanat festivallerinde yapıldığı görülmektedir. Bir müzik festivali kapsamında araştırma yapan Mehmetoglu ve Engen'in (2011) çalışmasında sadece müzik festivali değil, müze ziyaretleri kapsamında da deneyim ekonomileri modeli test edilerek kıyaslama yapılmıştır. Çalışma, deneyimin baskın boyutlarının uygulama alanına göre değiştiğini göstermektedir. Buna göre müze ziyaretçileri eğlence ve eğitim deneyimleri yaşarken, müzik festivali katılımcıları da ortam ilişkisinin oldukça yoğun olduğu estetik ve kaçış deneyimleri yaşamaktadır.

Festival özelinde deneyim ekonomileri modelini inceleyen diğer çalışmalardan biri de film festivali kapsamında uygulama yapan Park vd.'nin (2010) araştırmalarıdır. Çalışmada kaçı̧̧ deneyimlerinin, diğer deneyim boyutları üzerinde açılayıcı etkisi olduğu görülmüştür. Film festivalleri özelinde bir diğer çalışmada ise Yolal vd., (2019) festival deneyiminin temel olarak yenilik arayışı etrafında şekillendiğini saptamışlardır. Manthiou vd., (2014) ise etkinlik 
deneyimlerinin, hatırlanabilir olma özelliği aracılığında sadakat üzerine etki ettiğini ortaya koymuştur. Ayrıca bu çalışmada deneyimin bazı boyutlarının sadakat üzerinde etkileri olduğu görülmektedir. Bu boyutlar eğlence ve estetik boyutlarıdır. Son olarak Dieck vd., (2018) uygulamasını bilimsel bir etkinlik dahilinde gerçekleştirerek artırılmış gerçeklik deneyimlerini sorgulamıştır. Çalışmada estetik deneyimlerin, diğer deneyimleri açıklayıcı etkisi olduğu görülmüştür.

Sonuç olarak deneyim ekonomilerini model alan çalışmalarda deneyimlerin baskınlık ya da önemlilik seviyesinin, etkinlik konusuna göre değiştiği görülmektedir. Dahası bir etkinlik ortamında farklı deneyimler yaşanabildiği izlenmektedir. Dolayısıyla festival katılımcılarının kendi içinde alt gruplara ayrılabileceği düşünülmektedir. Bu alt gruplara ilişkin detaylı bilgilerin, arz sağlayıcıların rakiplerine göre avantaj elde etmesi ve daha iyi hizmet sunabilmesi adına faydalı olması beklenmektedir.

\section{YÖNTEM}

Çalışmanın alan araştırması, 1-4 Ağustos 2019 tarihlerinde Sinop'ta gerçekleşen Kuzeyfest Rock Müzik Festivali kapsamında gerçekleştirilmiştir. Sinop, Türkiye İstatistik Kurumu'nun 2018 verilerine göre, Türkiye'de en mutlu insanların yaşadığı kent olarak bilinmektedir (www.tuik.gov.tr). Türkiye'nin kuzeyinde yer alan, doğal güzellikleri ile ön plana çıkan Sinop'un, Sinop Valiliği'ne göre 2018 nüfusu yaklaşık 220 bin kişidir (www.sinop.gov.tr). Festival Kuzeyfest etkinliği gibi geniş katılımcı organizasyonlar Sinop'ta nadiren yapılmaktadır. Organizasyon sorumlularının ifade ettiği üzere etkinliğe 25 ilden 50 bine yakın katılım sağlanmıştır. Dolayısıyla 4 gün süren etkinlik şehre turistik hareketlilik ve ekonomik katkı sağlamıştır. Etkinlik alanı şehrin önemli çekiciliklerinden biri olan Akliman Plajı́nda kurulmuştur. Katılımcılar, konaklamalarını alanın içinde bulunan kamp alanında gerçekleştirmiştir. Ayrıca etkinlik alanı ve etrafında yeme-içme hizmetleri sunulmuştur. Dolayısıyla katılımcılara bütünleşik bir ürün sunulduğu gözlenmiştir.

Araştırmanın verileri, yüz yüze anket tekniği ile elde edilmiştir. Açık alan festival ortamında olasılıklı örnekleme yapmanın olanaksız olması (Gannon, Taheri ve Olya, 2019) ve katılımcı sayısının tam olarak bilinmemesi nedenlerinden ötürü olasılıksız örnekleme tekniklerinden kolayda örneklemeye başvurulmuştur. Kullanılabilir 303 anket elde edilmiştir.

Soru formunda festival deneyimlerinin belirlenmesi amaciyla 16 maddeden oluşan Oh vd., (2007) deneyim ölçeği kullanılmıştır. Sorular beşli Likert ölçeği ile sorulmuştur. Soru formunda katılımcıların cinsiyet, yaş, eğitim seviyesi, meslek ve medeni durumlarından oluşan sosyodemografik özelliklerine ilişkin sorulara yer verilmiştir.

Analiz öncesinde veri hazırlık süreci kapsamında sırasıyla aşırı değer, kayıp değer ve normal dağılım incelemeleri yürütülmüştür. İlk olarak standartlaştırılmış z değerlerine bakılarak tespit edilen 33 anket aşırı değer taşıması nedeniyle veri setinden çıkarılmıştır (Çokluk, Şekercioğlu ve Büyüköztürk, 2012). İkinci olarak kayıp değer oranının \%1'in altında olduğu görülmüş ve kayıp değerler için veri seti ortalamalarının ataması yapılmıştır (Hawthorne ve Elliot, 2005). Son olarak hem tek değişkenli hem de çok değişkenli normal dağılım incelemesi yapılmıştır. Buna göre veri setinde basıklık ve çarpıklık değerlerinin \pm 2 aralığında olduğu görülmüş ve tek değişken normal dağılım şartı sağlandığı kaydedilmiştir (Cameron, 2004:544; George ve Mallay, 2003:98). Daha sonra Mahalanobis $x^{2}$ dağılımı incelenerek çok değişkenli normal dağılım şartının sağlandığı görülmüştür. Hazır olan veri seti üzerinde SPSS 21 programı kullanılarak betimsel analiz, faktör analizi, kümeleme analizi, ki-kare ve t-test uygulanmıştır. 
Kümeleme analizi, temel amacı nesneleri sahip oldukları özelliklere göre gruplara ayırmak olan çok değişkenli istatistiksel bir analiz tekniğidir (Hair, Black, Babin ve Anderson, 2010). Kümeleme analizinin uygulanacağı değişkenlerin hem niteliksel hem de niceliksel değişkenlerden oluşması durumunda, kümeleme tekniklerinden iki aşamalı kümeleme analizi kullanılmaktadır (Alpar, 2011: 338). Bu yöntem pazar bölümlendirme çalışmalarında sıklıkla tercih edilmektedir (Tkaczynski, 2017). Buradan hareketle bu çalışmada da iki aşamalı kümeleme analizine başvurularak etkinlik katılımcılarının homojen gruplara dağılımı incelenmiştir. Kümeler arası farklılıkların istatistiksel olarak öneminin test edilmesinde ise ki-kare ve t-testine başvurulmuştur.

\section{BULGULAR}

Katılımcıların demografik özelliklerine ilişkin bulgular Tablo 1'de sunulmaktadır. Buna göre Nispeten erkek katılımcılar (\%54) çoğunluktadır. Katılımcıların yaş dağılımları 16 ve 61 yaş arasında değişmekle birlikte ortalama yaş $23^{\prime}$ dür. Diğer yandan medeni durumlarına bakıldığında bekar katılımcıların çoğunlukta olduğu anlaşılmaktadır (\%81). Eğitim düzeyleri incelendiğinde de katılımcıların çoğunluğunun (\%71) orta okul ve daha düşük bir eğitim seviyesine sahip oldukları görülmektedir. Öne çıkan bir başka bulgu ise katılımcıların neredeyse yarısına yakını öğrencidir (\%45).

Tablo 1. Katılımcların Demografik Özellikleri

\begin{tabular}{|c|c|c|c|c|c|}
\hline Değişkenler & $\mathbf{n}$ & $(\%)$ & Değişkenler & $\mathbf{n}$ & $(\%)$ \\
\hline Yaş $(n=303)$ Ortama $=23,98$ & 301 & 99,3 & Medeni Durum $(n=303)$ & & \\
\hline \multirow{2}{*}{ Kayıp değer } & 2 & 0,7 & Evli & 43 & 14,2 \\
\hline & & & Bekar & 234 & 77,2 \\
\hline \multicolumn{3}{|l|}{ Cinsiyet ( $n=303)$} & Kayıp değer & 26 & 8,6 \\
\hline Kadın & 134 & 44,2 & & & \\
\hline Erkek & 164 & 54,1 & \multicolumn{3}{|l|}{ Çalışma Durumu (n=303) } \\
\hline \multirow[t]{2}{*}{ Kayıp değer } & 5 & 1,7 & Memur & 31 & 10,2 \\
\hline & & & Öğrenci & 134 & 44,2 \\
\hline Ĕ̆itim Durumu (n=303) & & & İşçi & 52 & 17,2 \\
\hline Orta okul ve altı & 218 & 71,9 & İşsiz & 58 & 19,1 \\
\hline Ön lisans ve lisans & 62 & 20,5 & İşveren & 11 & 3,6 \\
\hline Lisansüstü & 19 & 6,3 & Serbest meslek & 13 & 4,3 \\
\hline Kayıp değer & 4 & 1,3 & Kayıp değer & 4 & 1,3 \\
\hline
\end{tabular}

Çalışmada ele alınan festival deneyim boyutlarının yapı geçerliliğinin sağlanması için öncelikle açıklayıcı faktör analizi yapılmıştır. Faktör analizinin gerekliliği olarak Kaiser-Meyer-Olkin (KMO) test sonucu 0,84'dür. Pallant'a (2011) göre oldukça iyi olan bu değer, faktör analizi için yeterli örneklem hacmine ulaşıldığını göstermektedir. Uygulanan Bartlett Test de değişkenler arası anlamlı düzeyde doğrusal bir ilişki olduğunu göstermektedir. Daha sonra Temel Birleşenler ve Oblimin döndürme tekniklerine başvurularak faktör analizi yapılmıştır. Faktör analizi sonuçları ve içsel tutarlılığı gösteren Cronbach $\alpha$ test sonuçları Tablo 2'de görülmektedir. Buna göre ölçeğin geneli ve alt faktörler kabul edilebilir limit olan $0,60^{\prime}$ ın oldukça üzerinde, iyi seviyededir (Hair vd., 2010). 
Açıklayıcı faktör analizi sırasında binişik faktör yükü olan maddeler çıkarılmıştır (Hair vd., 2010:118). Sonuç olarak 13 maddeyi içeren 4 faktörlü bir desen elde edilmiştir. Toplam açılanan varyans düzeyinin $(0,84)$ ise oldukça yüksek olduğu görülmektedir (Dunteman, 1989). Deneyim faktörleri önem sırasına göre estetik (ort. 4,08), eğlence (ort. 4,03), kaçış (ort. 3,91) ve eğitim (ort. 3,42) şeklindedir. Bulgular katılımcıların çeşitli deneyimleri bir arada yaşadıklarını göstermektedir. Ancak en fazla pasif katılım yoluyla ortaya çıan estetik ve eğlence deneyimleri yaşanmıştır.

Tablo 2. Etkinlik Deneyimleri Açıklayıcı Faktör Analizi Sonuçları

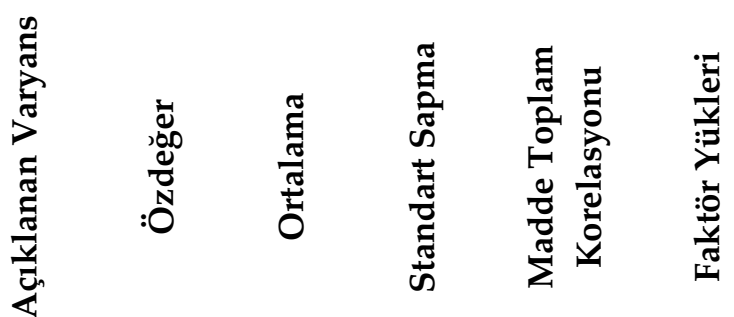

Faktör ve Maddeler

\begin{tabular}{|c|c|c|c|c|c|c|}
\hline Ĕgitim $(\alpha=0,971)$ & 46,404 & 6,032 & 3,42 & & & \\
\hline Çok şey öğreniyorum. & & & 3,41 & 1,280 & ,758 & ,926 \\
\hline $\begin{array}{l}\text { Etkinlik yeni şeyler öğrenmeye teşvik } \\
\text { ediyor. }\end{array}$ & & & 3,45 & 1,275 & ,769 & ,971 \\
\hline Bilgi düzeyim artıyor. & & & 3,44 & 1,267 & ,769 & ,981 \\
\hline $\begin{array}{l}\text { Gerçek bir öğrenme deneyimi } \\
\text { yaşıyorum. }\end{array}$ & & & 3,42 & 1,284 & ,778 & ,960 \\
\hline Estetik $(\alpha=0,845)$ & 21,328 & 2,773 & 4,08 & & & \\
\hline Her şey uyum içinde görünüyor. & & & 4,06 & 620 &, 500 & ,831 \\
\hline Burada olmaktan çok keyif alıyorum. & & & 4,18 & 626 & ,375 & ,931 \\
\hline Ortam çok ilgi çekici. & & & 4,03 &, 772 &, 568 & ,702 \\
\hline Ĕglence $(\alpha=0,754)$ & 10,493 & 1,364 & 4,03 & & & \\
\hline Sahne alan sanatçıları izlemek zevkli. & & & 4,49 & 655 & 127 & ,842 \\
\hline Büyüleyici etkinlikler oluyor. & & & 4,44 & 692 & 182 & ,923 \\
\hline $\begin{array}{l}\text { Sahne alan sanatçıları izlemekten çok } \\
\text { keyif alıyorum. }\end{array}$ & & & 3,98 & 851 & ,545 & ,649 \\
\hline Kaçış $(\alpha=0,920)$ & 6,449 & 838 & 3,91 & & & \\
\hline $\begin{array}{l}\text { Başka bir zaman ve mekânda } \\
\text { yaşıyormuşum gibi geliyor. }\end{array}$ & & & 3,86 & 867 & ,744 &,- 808 \\
\hline $\begin{array}{l}\text { Kendimi başka biri gibi hayal etmemi } \\
\text { sağlıyor. }\end{array}$ & & & 3,88 &, 882 & 766 &,- 917 \\
\hline Kendimi farklı biri gibi hissediyorum. & & & 3,99 & 840 & 691 &,- 920 \\
\hline Toplam $(\alpha=0,894)$ & 84,671 & & & & & \\
\hline
\end{tabular}

Yapı geçerliliğinin sağlandığını gösteren faktör analizi sonrasında iki aşamalı kümeleme analizi uygulanmıştır. Eğlence, estetik, kaçış ve eğitim boyutlarını içeren etkinlik deneyimlerine ek olarak yaş, cinsiyet, medeni durum, eğitim ve çalışma durumları birlikte küme analizine alınmıştır. Gerçekleştirilen analiz sonrasında etkinlik katılımcılarının iki kümeye ayrıldığı görülmüştür. Kümelere ilişkin istatistik bilgileri Tablo 3'de yer almaktadır. 
Ki-kare ve t-testlerine uygulanarak değişkenlere göre küme gruplarının anlamlı bir şekilde farklılaştı̆̆ı görülmüştür. Buna göre festival katılımcıları çalışma durumu, eğitim durumu, medeni durum, yaş değişkenlerinin yanı sıra eğlence deneyimi, kaçış deneyimi ve eğitim deneyimlerine göre küme bazında farklılık göstermektedir $(p<0,001)$. Estetik deneyimler ve cinsiyet deneyimlerinde ise kümeler arası anlamlı bir farklılık görülmemiştir $(p>0,05)$. Anlamlı farkların tespit edildiği değişkenler dikkate alınarak kümeler için isimlendirme yapılmıştır. Kümeler, kendi içinde öne çıkan deneyim boyutlarına göre "pasif deneyimci" ve "aktif deneyimci" şeklinde adlandırılmıştır.

Tablo 3. Kümeleme Analizi ve Farklılık Testleri Sonuçları

\begin{tabular}{|c|c|c|c|c|c|c|}
\hline \multirow[t]{3}{*}{ Değişkenler } & \multicolumn{2}{|c|}{$\begin{array}{l}\text { 1. Küme: Aktif } \\
\text { Deneyimci }\end{array}$} & \multicolumn{2}{|c|}{$\begin{array}{l}\text { 2. Küme: Pasif } \\
\text { Deneyimci }\end{array}$} & \multicolumn{2}{|c|}{$\begin{array}{c}\text { Farklılık test } \\
\text { sonuçları }\end{array}$} \\
\hline & \multicolumn{2}{|c|}{$\% 55,3 \quad 141$ katılımc1 } & \multicolumn{2}{|c|}{$\% 44,7 \quad 114$ katılımcı } & \multirow[b]{2}{*}{$t$-değeri } & \multirow[b]{2}{*}{$P$ değer } \\
\hline & Ortalama/Medyan & $n$ & Ortalama/Medyan & $n$ & & \\
\hline \multicolumn{7}{|l|}{ Deneyimler } \\
\hline $\begin{array}{l}\text { Estetik } \\
\text { deneyim }\end{array}$ & 4,03 & & 4,16 & & $-1,78$ & $0,075^{a}$ \\
\hline $\begin{array}{l}\text { Eğlence } \\
\text { deneyimi }\end{array}$ & 4,17 & & 4,50 & & $-4,63$ & $0,000^{a}$ \\
\hline Kaçış deneyimi & 4,02 & & 3,82 & & 2,06 & $0,041^{\mathrm{a}}$ \\
\hline $\begin{array}{l}\text { Eğitim } \\
\text { deneyimi }\end{array}$ & 3,72 & & 3,04 & & 4,50 & $0,000^{a}$ \\
\hline Yaş & 26,03 & & 20,84 & & 8,34 & $0,000^{a}$ \\
\hline Cinsiyet & Erkek & & Erkek & & & $0,420^{\mathrm{b}}$ \\
\hline Kadın & & 64 & & 47 & & \\
\hline Erkek & & 77 & & 67 & & \\
\hline Medeni durum & Bekar & & Bekar & & & $0,000^{b}$ \\
\hline Bekar & & 101 & & 114 & & \\
\hline Evli & & 39 & & 0 & & \\
\hline Eğitim durumu & $\begin{array}{l}\text { Orta öğretim ve } \\
\text { altı }\end{array}$ & & $\begin{array}{c}\text { Orta öğretim ve } \\
\text { altı }\end{array}$ & & & $0,000^{b}$ \\
\hline $\begin{array}{l}\text { Orta öğretim } \\
\text { ve altı }\end{array}$ & & 73 & & 114 & & \\
\hline $\begin{array}{l}\text { Önlisans ve } \\
\text { lise }\end{array}$ & & 48 & & 0 & & \\
\hline Lisansüstü & & 15 & & 0 & & \\
\hline Çalışma durumu & İşçi & & Öğrenci & & & $0,000^{b}$ \\
\hline Memur & & 24 & & 0 & & \\
\hline Öğrenci & & 8 & & 114 & & \\
\hline İşçi & & 43 & & 0 & & \\
\hline İşsiz & & 46 & & 0 & & \\
\hline İşveren & & 10 & & 0 & & \\
\hline Serbest meslek & & 10 & & 0 & & \\
\hline
\end{tabular}

a T-test sonucunda ulaşılan anlamlılık değeri

b Pearson Chi-Square test sonucunda ulaşılan anlamlılık değeri 
Pasif deneyimci katılımcıların tamamının orta öğretim ve altı eğitim düzeyine sahip öğrencilerden oluştuğu görülmektedir. Yaş ortalamaları 20,8 olan bu grubun üniversite ve lise öğrencilerinden oluştuğu anlaşılmaktadır. Ayrıca grubun tamamı bekardır. Bu grupta yer alan katılımcılar yoğunlukla pasif deneyim olan eğlence ve estetik deneyimleri yaşamaktadır. Ancak bu katılımcıların diğer gruba kıyasla daha fazla eğlence deneyimi yaşadığı görülmüştür $(p<0,001)$. Diğer yandan bu grubun aktif deneyimler olan kaçış ve eğitim deneyimlerini diğer gruba göre daha az yaşadıkları anlaşılmaktadır $(\mathrm{p}<0,05)$.

Aktif deneyimci katılımcılara bakıldığında, eğitim düzeyinin çeşitlilik gösterdiği görülmektedir. Bu grupta çoğunlukla orta öğretim ve altı eğitim düzeyine sahip katılımcılar yer alsa da bu grubun büyük bir kısmı üniversite eğitimi almış katılımcılardan oluşmaktadır. Benzer şekilde aktif deneyimcilerin çalışma durumu da oldukça farklılaşmaktadır. Ancak çoğunlukta bu katılımcıların işçi oldukları kaydedilmiştir. Aktif katılımcıların da çoğunluğu bekardır ancak evli olan katılımcılar da bulunmaktadır. Yaşadıkları deneyimlere bakıldığında bu grup üyelerinin de en fazla eğlence ve estetik deneyimler yaşadığı görülmüştür. Ancak aktif deneyimciler, pasif deneyimcilere kıyasla daha az eğlence deneyimi yaşamaktadırlar $(p<0,001)$. Dahası aktif katılımcıların diğer gruba kıyasla daha fazla kaçış ve eğitim deneyimleri yaşadığı belirlenmiştir $(\mathrm{p}<0,05)$.

\section{TARTIŞMA SONUÇ VE ÖNERILER}

Çalışmada geniş katılımlı bir müzik festivali olan Kuzeyfest Rock Müzik Festivali'nde alan uygulaması yapılarak katılımcıların deneyimlerine göre sınıflandırılması üzerine inceleme yapılmıştır. Bu kapsamda çalışmada festival katılımcılarının deneyimlerinin belirlenmesinde başvurulan deneyim ekonomileri yaklaşımının, oldukça güçlü bir şekilde festival deneyimlerini açıklayabildiği görülmüştür.

İlk olarak festival deneyimi faktörlerine bakıldığında, Kuzeyfest Rock Müzik Festivali'nde eğitim, estetik, eğlence ve kaçış deneyimleri yaşandığı sonucuna ulaşılmıştır. Diğer yandan deneyim ekonomileri yaklaşımıla farklı turistik uygulamalarda turist deneyimini inceleyen çalışmalarda ulaşılan sonuçlar farklılaşmaktadır. Örneğin golf turnuvası katılımcılarında eğitim, eğlence ve kaçış deneyimi yaşanırken estetik deneyimler boyutu anlamlı değildir (Hwang ve Lyu 2015). Benzer şekilde doğa etkinliklerine katılan katılımcıların da istatistiksel olarak anlamlı bir şekilde eğitim, estetik ve kaçış deneyimleri yaşarken eğlence deneyimleri yaşamadığ görülmüştür (Aşan ve Emeksiz, 2018). Ancak bu çalışmada deneyim ekonomileri modelinde önerilen dört deneyim boyutunun da uygulamada karşılığı olduğu anlaşılmaktadır. Ayrıca literatürdeki çalışmalarda deneyim boyutlarının önem sırasının da farklılaştığı görülmektedir. Bu bağlamda farklı turistik ya da rekreatif etkinliklerde deneyim boyutlarının etkinliğin yapısal özeliklerine göre değişebileceği anlaşılmaktadır. Buna göre Pine ve Gilmore (2011) önerdiği gibi zengin deneyimler için deneyimin tüm boyutlarını kapsayacak şekilde hizmet sunulmasının her durumda anlamlı olmayabileceği anlaşılmaktadır.

Araştırma sonuçlarından bir diğeri de katılımcıların en çok yaşadıkları deneyimin, estetik deneyim olmasıdır. Literatüre bakıldığında da konusu farklılaşan çeşitli festival etkinliklerinde estetik deneyimin öne çıktığı görülmektedir (Dieck vd., 2018; Manthiou vd., 2014; Mehmetoğlu ve Engen 2011; Park vd., 2010). Estetik deneyimler, katılımclların festival ortamını ve fiziksel unsurları değerlendirmelerini ifade etmektedir. Estetik deneyimlerde katılımclar pasif olarak festival ortamında var olan etkinlikleri izlemekte ve izlenim edinmektedir. Dolayısıyla festival programı dahilinde sunulan performansları izleyici konumda olan katılımcılar için bu deneyim türünün baskın olması anlamlıdır. Dieck'in (2018) estetik deneyimlerin toplam deneyimler içinde önemli bir öncül değişken olduğunu gösteren çalışması dikkate alındığında estetik deneyimlerin, 
güçlü deneyimler olduğu anlaşılmaktadır. Bu bağlamda çalışmanın sonuçları literatürle birlikte değerlendirildiğinde festival etkinliklerinde estetik deneyimlerin en önemli deneyimler olduğu anlaşılmaktadır. Bu durumu destekleyecek şekilde çalışmada yapılan analizler katılımcıların estetik deneyimler dışındaki deneyim boyutlarında anlamlı bir şekilde farklılaştığını gösterirken, tüm katılımcların benzer ve yüksek düzeyde estetik deneyimler yaşadığı görülmü̈ştür.

Çalışmanın amacı doğrultusunda uygulanan kümeleme analizi sonucunda, deneyim ekonomi modelinin teorik çerçevesine uygun olarak katılımcıların "aktif deneyimci" ve "pasif deneyimci" olmak üzere iki grupta yer aldığı sonucuna ulaşılmıştır. Buna göre ilk olarak pasif deneyimlere bakıldığında, bu grupta yer alan katılımcıların eğitim düzeylerinin düşük, genç, bekar ve öğrenci oldukları görülmektedir. Estetik deneyimde anlamlı bir farklılık olmasa da bu grubun aktif deneyimcilere göre daha fazla eğlence deneyimi yaşadığı anlaşılmaktadır. Diğer yandan kaçış ve eğitim deneyimlerinin diğer gruba göre anlamlı bir şekilde düşük olduğu görülmüştür. Deneyim ekonomileri modeline göre kaçı̧s ve eğitim deneyimlerinde katılımcıların aktif bir şekilde etkinlik ortamına katılım göstermesi beklenmektedir. Ancak burada katılımclların nispeten pasif bir katılım gösterdikleri anlaşılmaktadır. Bu duruma uygun olarak bu grubun isimlendirilmesi "pasif deneyimciler" şeklinde yapılmıştır.

Aktif deneyimciler grubuna bakıldığında ise katılımcıların eğitim düzeyinin daha yüksek olabildiği, yaş ortalamasının yükseldiği, çalışma hayatında yer aldıkları, çoğunlukla bekar oldukları görülmektedir. Bu grupta yer alan katılımcıların, deneyim ekonomileri modeline göre festival ortamına aktif katılım gerektiren eğitim ve kaçış deneyimlerini diğer gruba kıyasla daha çok yaşadığı anlaşılmaktadır. Buna göre bu grupta yer alan bireylerin eğitim seviyesinin yüksek olması, eğitim deneyimlerine karşı daha duyarlı olmalarıyla açıklanabilir. Diğer yandan kaçış deneyimleri, olağan yaşamın dışına çıkma isteğiyle açıklanmaktadır (Rivera vd., 2015; Iso-Ahola, 1983). Çoğunlukla eğitimini tamamlamış ve çalışma hayatına girmiş aktif deneyimcilerin yaşamlarının olağan bir düzen içinde olduğu, bu nedenle diğer gruba kıyasla daha fazla kaçış deneyimi yaşadıkları düşünülebilir.

Çalışmada ulaşılan sınıflandırma müzik festivali organizatörlerinin, hedef pazarı daha iyi anlamaları için bir temel oluşturmaktadır. Her ne kadar festival katılımclarının genelde genç, bekar ve öğrenci oldukları ve çoğunlukla estetik deneyimler yaşadığı görülse de kendi içinde anlamlı bir şekilde alt gruplara ayrıldığı ortaya konmuştur. Buna göre aktif deneyim katılımcıları festival ortamında sadece izleyici olarak kalmak istememekte, olağan hayatlarını değiştirebilecek, anlam katacak, yeni şeyler öğrenebilecekleri, daha etkin olabilecekleri deneyimler yaşamaktadır. Organizatörler bu grupta yer alan katılımcılara hitap edecek özel aktivite ve uygulamaları festival programlarına dahil edebilirler. Örneğin bir müzik festivalinde, ziyaretçilerin kendi performanslarını sergileyebilecekleri, enstrüman deneyebilecekleri butik sahneler inşa edilebilir. Bu anlamda simülasyon teknolojisi ile geliştirilmiş oyun alanları kurulabilir. Benzer şekilde katılımcıların kendilerini farklı hissedebilmeleri için sahne aydınlatmalarının yanı sıra izleyicilerin bulunduğu alanda da çeşitli aydınlatma ve ışık oyunları kullanılabilir. Dahası festival alanının bir uzantısı olabilecek yeni medya ortamlarında ve sosyal medya uygulamalarında iyi düşünülmüş etiketlendirmelerle etkinlik güçlendirilebilir. Böylece bu etiketlerle sosyal medyada içerik üreterek paylaşım yapan katılımcılar, aktif bir şekilde festivalin pazarlanmasına katkı sağlayabilir.

Pasif deneyimciler için de çeşitli uygulamalar geliştirilebilir. Bu grup aktif deneyimciler kadar girişken olmasa da kendilerine hitap edecek destek hizmetlerden faydalanabilirler. Eğlenme deneyimlerini çoğaltmak üzere festival alanında kurulacak oyun alanları faydalı olacaktır. Estetik deneyimlerin çoğaltılması ise hem aktif hem pasif deneyimciler için önem arz etmektedir. $\mathrm{Bu}$ anlamda festival alanında sunulan hizmet, hizmetin kalitesi, alanın tasarımı ve sunumu gibi unsurlar hayati öneme sahiptir. Organizatörlerin bu konularda titizlikle planlama ve uygulama 
yapması gerekmektedir. Ayrıca festival temasının, festival alanında görülebilecek tüm materyallerde bütünlükçü bir anlayışla işlenmesi hem görsel sunum anlamında hem de etkinliğin akılda kalıcılığı anlamında fark yaratacaktır.

Çalışmanın etkinlik katılımcılarının kendi içinde sınıflandırılabileceğine ilişkin ampirik kanıtlar sunarak literatürü katkı sunduğu düşünülmektedir. Ancak çalışmanın uygulaması bir müzik etkinliği olan tek bir festival ile sınırlıdır. Farklı coğrafyalarda farklı türde festival etkinliklerini kapsayan daha geniş örneklemde çalışmalar yapılabilir. Gelecek pazar bölümlendirme çalışmalarında deneyimlerin yanı sıra motivasyon, yaşam tarzı, kişilik gibi başka tüketici davranışı değişkenleri bir arada incelenebilir.

\section{KAYNAKÇA}

Alpar, R. (2011). Uygulmalı çok değiş̧kenli istatiksel yöntemler. Ankara: Detay Yayıncılık.

Arnould, E. J. and Price, L. L. (1993). River magic: extraordinary experience and the extended service encounter, Journal of Consumer Research, 20(1): 24-45.

Aşan, K. and Emeksiz, M. (2018). Outdoor recreation participants' motivations, experiences and vacation activity preferences, Journal of Vacation Marketing, 24(1): 3-15.

Cameron, A. (2004). Kurtosis (Editör) Lewis-Beck, M., Bryman, A. and Liao, T.: Encyclopedia of Social Science Research Methods içinde (ss. 544-545) California: Sage Publications.

Çokluk, Ö., Şekercioğlu, G. ve Büyüköztürk, Ş. (2012). Sosyal bilimler için çok değişkenli istatiksel spss ve lisrel uygulamaları. Ankara: Pegem Akademi.

Dieck, M. C., Jung, T. H., and Rauschnabel, P. A. (2018). Determining visitor engagement through augmented reality at science festivals: An experience economy perspective, Computers in Human Behavior, 82: 44-53.

Dolnicar, S. and Kemp, B. (2009). Tourism segmentation by consumer-based variables (Editör) Kozak M. ve Decrop, A.). Handbook of Tourist Behavior içinde (ss.177-195) New York: Routledge.

Duan, B., Arcodia, C., Ma, E. and Hsiao, A. (2018) Understanding wine tourism in China using an integrated product-level and experience economy framework, Asia Pacific Journal of Tourism Research, 23(10): 949-960.

Dunteman, G.H. (1989). Principal component analysis. Quantitative applications in the social sciences series (vol. 69). Thousand Oaks, California: Sage Publications.

Elands, B. H. and Lengkeek, J. (2012). The tourist experience of out-there-ness: Theory and empirical research, Forest Policy and Economics, 19: 31-38.

Eser, Z., Korkmaz, S. ve Öztürk, A. (2011). Pazarlama Kavramlar İlkeler Kararlar. Ankara: Siyasal Kitabevi.

Gannon, M., Taheri, B. and Olya, H. (2019). Festival quality, self-connection, and bragging, Annals of Tourism Research, 76: 239-252.

George, D. and Mallery, P. (2003). SPSS for Windows step by step: A simple guide and reference 11.0 update. Boston: Allyn and Bacon.

Getz, D. (2008). Event tourism: Definition, evolution, and research, Tourism Management, 29 (3): 403-428. 
Grappi, S. and Montanari, F. (2011). The role of social identification and hedonism in affecting tourist patronizing behaviors: the case of an Italian festival, Tourism Management, 32: 1128-1140.

Gursoy, D., Kim, K. and Uysal, M. (2004). Perceived impacts of festivals and special events by organizers: An extension and validation, Tourism Management, 25(2): 171-181.

Hair, J. F., Black, W., Babin, B. and Anderson, R. (2010). Multivariate Data Analysis. Pearson Education: New Jersey.

Hawthorne, G. and Elliott, P. (2005). Imputing cross-sectional missing data: Comparison of common techniques, Australian and New Zealand Journal of Psychiatry, 39: 583-590.

Holbrook, M. B. and Hirschman, E. (1982). The experiential aspects of consumption: consumer fantasies, feelings, and fun, Journal of Consumer Research, 9(2): 132-140.

http://www.tuik.gov.tr/PreHaberBultenleri.do?id=18629 (Erişim tarihi: 20.01.2020)

http://www.sinop.gov.tr/demografik-yapi (Erişim tarihi: 20.01.2020)

Hwang, I. and Lee, J. (2019). A strategy for enhancing senior tourists' well-being perception: focusing on the experience economy, Journal of Travel \& Tourism Marketing, 36(3): 314-329.

Hwang, J. and Lyu, S. O. (2015). The antecedents and consequences of well-being perception: An application of the experience economy to golf tournament tourists, Journal of Destination Marketing E Management, 4(4): 248-257.

Iso-Ahola, S. E. (1983). Towards a Social Psychology of Recreational Travel, Leisure Studies, 2: 4556.

Jung, T., Dieck, M. C., Lee, H. and Chung, N. (2016). Effects of virtual reality and augmented reality on visitor experiences in museum, Information and communication technologies in Tourism, Cham: Springer.

Kastenholz, E., Carneiro, M. J. and Eusébio, C. (2018). Diverse socializing patterns in rural tourist experiences-a segmentation analysis, Current Issues in Tourism, 21(4): 401-421.

Kim, R., Ritchie B. and McCormick B. (2012). Development of a scale to measure memorable tourism experiences, Journal of Travel Research, 51(1): 12-25.

Kotler, P. and Armstrong, G. (2010). Principles of Marketing. London: Pearson education.

Lee, B. and Shafer, C. S. (2002). The dynamic nature of leisure experience: An application of affect control theory. Journal of Leisure Research, 34(3): 290-310.

Lee, T. H., Jan, F. H., Tseng, C. H. and Lin, Y. F. (2018). Segmentation by recreation experience in island-based tourism: a case study of Taiwan's Liuqiu Island, Journal of Sustainable Tourism, 26(3): 362-378.

Manthiou, A., Lee, S., Tang, L. and Chiang, L. (2014). The experience economy approach to festival marketing: Vivid memory and attendee loyalty, Journal of Services Marketing, 28(1): 22-35.

Mehmetoglu, M. and Engen, M. (2011). Pine and Gilmore's concept of experience economy and its dimensions: An empirical examination in Tourism, Journal of Quality Assurance in Hospitality $\mathcal{E}$ Tourism, 12(4): 237-255.

Morgan, M. (2008). What makes a good festival? Understanding the event experience, Event Management, 12(1): 81-93.

Morrison, A. M. (1996). Hospitality and travel marketing. Albany: Delmar. 
Oh, H., Fiore, A. M. and Jeoung, M. (2007), Measuring experience economy concepts: Tourism applications, Journal of Travel Research, 46(2): 119-132.

Pallant, J. (2011). SPSS Survival Manual: A Step by Step Guide to Data Analysis Using SPSS, Sydney: Allen \& Unwin.

Park, M., Oh, H. and Park, J. (2010). Measuring the Experience Economy of Film Festival Participants, International Journal of Tourism Sciences, 10(2): 35-54.

Pine, B. and Gilmore, J. (1998). Welcome to the experience economy, Harvard Business Review, 76(4): 96-105.

Pine, J. ve Gilmore, J. (2011). Deneyim Ekonomisi. İstanbul: Optimist Yayınları.

Prentice, R. C., Witt, S. F. and Hamer, C. (1998). Tourism as experience, Annals of Tourism Research, 25(1): 1-24.

Reid, R. D. and Bojanic, D. C. (2006). Hospitality marketing management. New Jersey: John Wiley and Sons.

Rivera, M., Semrad, K. and Croes, R. (2015). The five E's in festival experience in the context of Gen Y: Evidence from a small island destination, Revista Española de Investigación de Marketing ESIC, 19(2): 95-106.

Sung, H. Y., Morrison, A. and O'Leary, J. (2001). Segmenting the adventure travel market by activities: From the North American industry providers' perspective, Journal of Travel \& Tourism Marketing, 9(4): 1-20.

Swarbrooke, J. and Horner: (2007). Consumer behaviour in tourism. Oxford: Elsevier.

Tkaczynski A. (2017). Segmentation Using Two-Step Cluster Analysis. (Ed: Dietrich T., RundleThiele S., Kubacki K.) Segmentation in Social Marketing. Springer: Singapore.

Toffler, A. (1981). The third wave. London: Pan Books.

Witt, S. F. and Moutinho, L. (1995). Tourism marketing and management handbook. New Jersey: Prentice.

Yolal, M. (2017). Türkiye'nin etkinlik turizmi potansiyelinin değerlendirilmesi, Uluslararası Turizm ve Sosyal Araştırmalar Dergisi, 2: 35-51.

Yolal, M., Özdemir, C., and Batmaz, B. (2019). Multidimensional scaling of spectators' motivations to attend a film festival, Journal of Convention \& Event Tourism, 20(1): 64-83.

Yükselen, C. (2010). Pazarlama ilkeler yönetim örnek olaylar. Ankara: Detay Yayıncllı. 